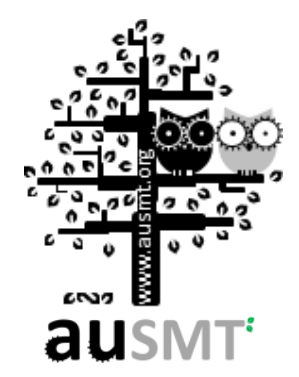

\title{
The Trend towards "Smart Cities"
}

\section{Chien-Chu Chen*}

Market Intelligence \& Consulting Institute (MIC), Institute for Information Industry (III), Taiwan

(Received 16 May 2014; Published on line 1 June 2014)

*Corresponding author: kevin3c@micmail.iii.org.tw

DOI: 10.5875 /ausmt.v4i2.741

Looking back over the past century, the steady pace of development in many of the world's cities has resulted in a situation where a high percentage of these cities are now faced with the problem of aging, decrepit urban infrastructure; a considerable number of cities are having to undertake large-scale infrastructure renewal projects. While creating new opportunities in the area of infrastructure, ongoing urbanization is also creating problems, such as excessive consumption of water, electric power and heat energy, environmental pollution, increased greenhouse gas emissions, traffic jams, and the aging of the existing residential housing stock, etc. All of these problems present a challenge to cities' ability to achieve sustainable development. In response to these issues, the concept of the "smart city" has grown in popularity throughout the world. The aim of smart city initiatives is to make the city a vehicle for "smartification" through the integration of different industries and sectors. As initiatives of this kind move beyond basic automation into the realm of real "smartification," the smart city concept is beginning to take concrete form.

\section{Smart city business opportunities are mushrooming everywhere}

In order to develop a comprehensive picture of the current state of smart city development throughout the world, the present study analyzes a total of 415 smart

www.ausmt.org

Copyright (C) 2014 International Journal of Automation and Smart Technology city development plans from different countries. For the purposes of this study, smart cities are divided into five broad categories: transportation-focused smart cities, energy-focused smart cities, building-focused smart cities, water-resources-focused smart cities, and governance-focused smart cities. However, it should be noted that a given smart city development plan will normally involve more than one of these categories. The study also undertakes a cross-regional comparison of smart city development plans. The study's findings were as follows:

The Asia Pacific region accounts for the largest share of all smart city development plans worldwide, with $51 \%$ of the global total. Smart city development plans in the Asia Pacific region tend to be energy-focused smart city initiatives, aimed at easing the pressure on energy resources that will be caused by continuing rapid urbanization in the future. In addition, many cities in those Asia Pacific countries that have benefited from the "population dividend" have been implementing governance-focused smart city projects, which emphasize improving public safety, reducing the incidence of urban disaster, and promoting citizens' health, with the aim of enhancing the overall quality of life of these cities' residents.

Energy-focused smart city development plans are also the most common type of smart city initiative in Europe and North America. In North America, there has been a major drive to introduce smart meters and smart 


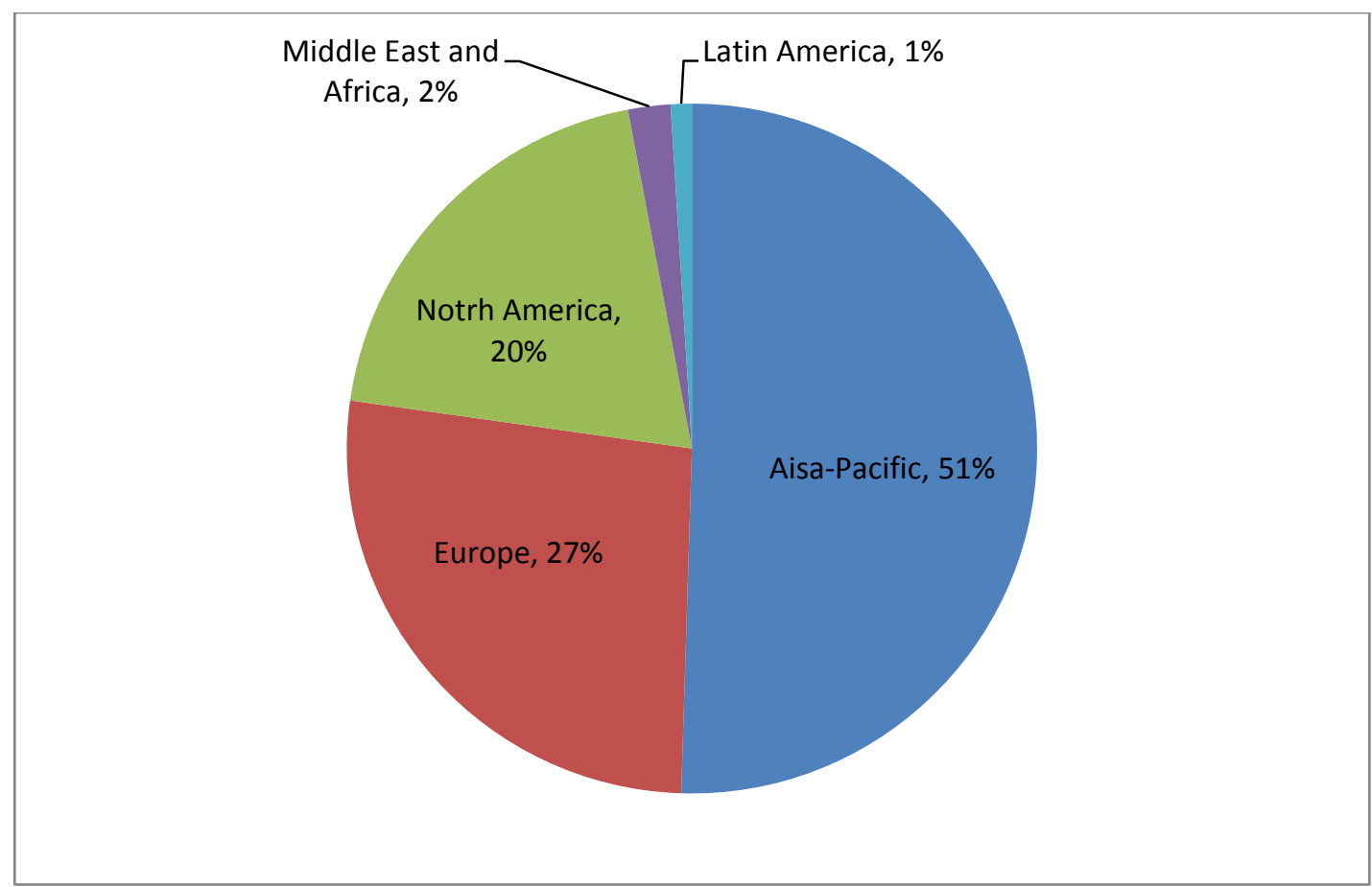

Figure 1. Smart City Development Plans, by Region.

Source: MIC, Institute for Information Industry, October 2013.

electric power grids, integrating the electric power sector with information and communications technology (ICT) and replacing obsolete electric power infrastructure, so as to make cities' electric power systems more reliable (which in turn can help to boost private-sector investment, stimulate the growth of the "green energy" industry, and create more job opportunities). In Europe, by contrast, the main focus is usually on boosting the use of renewable energy sources, with smart grids playing an ancillary role by facilitating adjustment of the off-peak power supply, thereby helping to achieve optimal allocation of electric power. Cities in Europe have also been working hard to develop smart transportation, promoting the adoption of next-generation electric vehicles while also introducing new types of car-sharing services; the aim here is to reduce the greenhouse gas emissions caused by commuting. These initiatives show the potential for smart city plans that effectively integrate "hardware" and "software" elements.

Chien-Chu Chen participated in the Research of Taiwan Industry and Technology Foresight Project sponsored by the Ministry of Economic Affairs, and has carried out research on The Impact of Changes in the Population Structure in Taiwan on Industrial Development, and on Enhancing Overall National Industrial Competitiveness - Exploring the Business Opportunities Associated with the "Smart City." He is currently responsible for implementation of the Energy Policy Strategy Division in Ministry of Science and Technology's National Energy Program-Phase II (NEP-II), having previously served as Research Assistant for the designing and developing the Campus Carbon Footprint Platform Systems (CCFPS) of National Energy Program-Phase I (NEP-I), and as Project Manager on the Multi Employment Promotion Project, Council of Labor Affairs Executive. He holds an M.Sc. in Industrial Management from National Pingtung University of Science and Technology.

\section{Innovative smart city solutions that integrate different forms of industrial technology}

The global trend towards continuing urbanization has brought with it almost unlimited business opportunities. Leading international corporations have been moving aggressively into the smart city market, seeking to take advantage of their accumulated experience to expand the amount of influence they are able to exert in the smart city sector. These big international corporations are able to offer a wide range of different products and services to meet the needs of different types of smart city initiative, and by integrating different forms of industrial technology they can provide solutions tailored to suit the requirements of each category of smart city. To transform a city into a smart city, the city first needs to undergo the stages of computerization and automation; it is only through technology integration and the development of value-added functions that the vision of a "uniformly smart" city can be achieved.

In the future, the business models on which industries have relied in the past will be tested more and more severely. The smart city movement has stimulated a new trend towards cross-industry collaboration; firms in different industries will have to work together to identify new business models that successfully integrate different forms of industrial technology, so as to create the automation and smartification products and services 
needed for smart city development. Only then will it be possible to satisfy local government authorities' needs in terms of the upgrading and renewal of their systems, and only then will it be possible for firms to secure maximum benefit from the new smart city business opportunities that can be expected to emerge in the future.

\section{Local government authorities - The chief promoters of smart city development}

As the trend towards smart cities sweeps the world, local government authorities throughout Taiwan have been promoting their own smart city initiatives. In Taiwan, local government authorities have extensive responsibilities in relation to city administration. With the number of Special Municipalities in Taiwan set to rise to six (Taipei City, New Taipei City, Taichung City, Kaohsiung City, Tainan City, and Taoyuan City), Taiwan's cities have been working to transform themselves into cities that effectively integrate living, production and ecological functions, thereby helping to create a better quality of life for their citizens; they anticipate that this transformation can also help to stimulate overall local development, enhancing the city's competitiveness, and helping to avoid a situation where the magnetic attraction of the six Special Municipalities leads to other, smaller cities becoming marginalized, which would exacerbate the existing disparities between Taiwan's more highly-urbanized regions and its less-urbanized regions.

Taipei City and Taichung City have both won first prize in the Intelligent Community Forum (ICF) Intelligent Community Award, in 2006 and 2013 respectively; in the 2014 Intelligent Community Award, both New Taipei City and Taoyuan City placed in the Top Seven. In the 2013 International Awards for Livable Communities, Kaohsiung City won more individual awards than any other city, while New Taipei City won a bronze medal in the Whole City category. These awards are testimony to the great strides that Taiwan's cities have made in terms of urban governance, and to the steady progress they have made towards transforming themselves into smart cities.

It should be noted that, in many countries, smart city initiatives benefit from proactive policy support on the part of local government authorities, which leverage government policy to attract private-sector resources and technology. Local government authorities work together with private-sector firms to jointly formulate effective business models for developing the products and services needed for smart city development, while striving to create a win-win situation for both the public and private sectors. Local government authorities in Taiwan have gradually begun to recognize the importance of ensuring that smart city development benefits both the public and private sectors, which is an encouraging sign.

\section{Conclusions: Strengthening the overall competitiveness of Taiwanese industry}

Cities in different parts of the world face different problems and challenges when it comes to urban development, making it necessary to utilize technology applications from different fields to solve the unique problems that each individual city has to overcome; the emphasis here is on the development of customized solutions for smart city development. If Taiwanese firms want to take advantage of the smart city business opportunities that are emerging throughout the world, their first priority will be to take on the challenge of developing service packages that integrate different sectors in a systematic way. Many city governments in Taiwan have launched smart city plans, and many Taiwanese firms have been actively involved in these projects. However, unsatisfactory horizontal linkages have resulted in a lack of effective inter-industry collaboration, creating a situation where individual firms achieve impressive results, but the results achieved by different firms are not coordinated properly. The implementation of smart city development plans in Taiwan has consequently so far not resulted in a "cluster effect" that brings together different smart city related firms in the same industry cluster; as a result, Taiwan has failed to develop integrated, comprehensive smart city solutions.

There is an urgent need to establish a "Smart City Industry Alliance" in Taiwan so as to break down the barriers that separate firms in different industries within Taiwan, stimulate cross-industry collaboration, and help Taiwanese firms to take full advantage of smart city business opportunities. With regard to the development of smart city related industries in Taiwan, an industry alliance of this kind could play an important "matching" role, bringing together firms from different industries and helping Taiwan gain maximum benefit from the many industries in which it has competitive advantage. Bringing together representatives of government agencies, universities, research institutes and leading domestic and international smart city solution providers to form a "Smart City Industry Alliance" would support the collaborative development of the total solutions needed for effective smart city development. These solutions could then be adopted in Taiwan's cities to verify the effectiveness of the products and services in question; the achievement of outstanding results in Taiwan would attract the interest of foreign governments, 
helping Taiwanese firms to develop international markets.

In recent years, Taiwan's cities have won many international awards, and this international recognition has encouraged representatives of city governments in other countries to visit Taiwan to see if they can learn from Taiwan's experience. Individual Taiwanese city governments will be vital partners for Taiwanese firms in smart city related industries that are seeking to develop international markets. By disseminating the results achieved by smart city initiatives in Taiwan, city governments will be able to implement effective "marketing" of their own cities, while also helping to bring together Taiwanese firms with city governments in other countries, enabling Taiwan to take full advantage of the smart city business opportunities that are mushrooming around the world. 